\title{
Different Localization of Two Types of Endothelin Receptor mRNA in Microdissected Rat Nephron Segments Using Reverse Transcription and Polymerase Chain Reaction Assay
}

\author{
Yoshio Terada, Kimio Tomita, Hiroshi Nonoguchi, and Fumiaki Marumo \\ Second Department of Internal Medicine, Tokyo Medical and Dental University, Tokyo 113, Japan
}

\begin{abstract}
Recent studies have revealed that endothelins (ETs) have at least two types of receptors. One receptor has high affinity to ET-1 and ET-2 and low affinity to ET-3 (A type). The other receptor binds almost equally to ET-1, ET-2, and ET-3 (B type). In this study, microlocalization of mRNA coding for the A-type and B-type ET receptors was carried out in the rat kidney using a reverse transcription and polymerase chain reaction assay of individual microdissected renal tubule segments along the nephron, glomeruli, vasa recta bundle, and arcuate arteries. Large signals for the B-type receptor polymerase chain reaction product were detected in the initial and terminal inner medullary collecting duct and the glomerulus, while small signals were found in the cortical collecting duct and outer medullary collecting duct, vasa recta bundle, and arcuate artery. In contrast, A-type receptor mRNA was detected only in the glomerulus, vasa recta bundle, and arcuate artery. Thus, the two ET receptor subtypes are distributed differently along the nephron. This suggests that the two types of receptors and ET families may affect kidney functioning in different ways. (J. Clin. Invest. 1992. 90:107-112.) Key words: reverse transcription • polymerase chain reaction • messenger RNA • glomerulus • inner medullary collecting duct
\end{abstract}

\section{Introduction}

Endothelin-1 (ET-1), ${ }^{1}$ initially described as a 21 -amino acid vasoactive peptide secreted by cultured vascular endothelial cells (1), is now known to be a family of three distinct peptides (2). ET-1 differs in structure from ET-2 and ET-3 by two and six amino acid residues, respectively (2). Recently, two distinct ET receptors (ET-Rs) were described (3-5), each belonging to

A portion of this study was presented at the 1991 Annual Meeting of the American Society of Nephrology, Baltimore, MD.

Address reprint requests to Dr. Terada, Second Department of Internal Medicine, Tokyo Medical and Dental University, 5-45, Yushima 1-chome, Bunkyo-ku, Tokyo 113, Japan.

Received for publication 4 October 1991 and in revised form 9 January 1992.

1. Abbreviations used in this paper: $\mathrm{CCD}$, cortical collecting duct; ET, endothelin; ET-R, ET receptor; Glm, glomeruli; GAPDH, glyceraldehyde-3-phosphate-dehydrogenase; IMCD, inner medullary collecting duct; similarly, iIMCD and tIMCD, initial and terminal parts, respectively, of the IMCD; OMCD, outer medullary collecting duct; PCR, polymerase chain reaction, $\mathrm{RT}$, reverse transcription.

J. Clin. Invest.

(C) The American Society for Clinical Investigation, Inc. 0021-9738/92/07/0107/06 \$2.00

Volume 90 , July $1992,107-112$ the superfamily of rhodopsin-like receptors, with seven transmembrane domains. One receptor (A-type ET-R) binds ET-1 with 2- to 10-fold higher affinity than ET-2 and with $>100$ fold higher affinity than ET-3 $(3,5)$. The other receptor (B-type ET-R) has similar affinities for all three peptides (4).

Many reports have been studied the renal action of ET-1. GFR and renal blood flow decrease and urinary flow rate increases after administration of ET-1 (6). ET-1 has also been reported to influence the function of the glomerulus (7) and inner medullary collecting duct $(8,9)$. Autoradiographic study revealed that the binding sites of ET-1 were mainly the glomerulus, vascular system, and renal medulla $(10,11)$. However, the receptor subtypes are not clear in the binding study. The presence of ET-R in the kidney has been confirmed by Northern blot analysis, which revealed that B-type ET-R mRNA was expressed in rat (4) and human kidney (12). A-type ET-R mRNA is also present in low amounts in rat (5) and bovine kidney (3). Because of the heterogeneity of the kidney, the Northern blot data did not give information about which parts of the nephron segments or renal structure have these receptor mRNAs. It seems very important to know the precise localization of both types of receptor expression along the nephron segments and renal vascular system in order to understand the renal actions of ETs.

Recently, Moriyama et al. (13) and Terada et al. (14) introduced a new method for measurement of relative levels of specific mRNA in single microdissected renal tubules in using the polymerase chain reaction (PCR) coupled to reverse transcription (RT-PCR). By using this technique, relative quantitation of mRNA coding for peptide hormone receptor was performed from only 2-mm lengths of renal tubules (14).

In the present study, we employed the RT-PCR technique for the precise localization of A-type and B-type ET-R mRNA in microdissected renal tubules, glomeruli (Glm), arcuate arteries, and vasa recta bundles.

\section{Methods}

Renal tubule microdissection. Male Sprague-Dawley rats weighing 75$100 \mathrm{~g}$ were killed by decapitation. The aorta was cannulated with polyethylene tubing below the left kidney, and the left kidney was perfused in vivo. The kidney was perfused initially with $10 \mathrm{ml}$ of ice-cold dissection solution (solution 1) and then with $10 \mathrm{ml}$ of the same solution containing $1 \mathrm{mg} / \mathrm{ml}$ collagenase (collagenase solution) (type I, $300 \mathrm{U} /$ $\mathrm{mg}$, Sigma Chemical Co., St. Louis, MO) and $1 \mathrm{mg} / \mathrm{ml} \mathrm{BSA} \mathrm{(Sigma}$ Chemical Co.). The dissection solution (solution 1) contained the following (mM): $135 \mathrm{NaCl}, 1 \mathrm{Na}_{2} \mathrm{SO}_{4}, 1.2 \mathrm{MgSO}_{4}, 5 \mathrm{KCl}, 2 \mathrm{CaCl}_{2}, 5.5$ glucose, and 5 Hepes (pH 7.4).

The left kidney was removed and a coronal section was made that contained the entire corticopapillary axis. This section was cut into four pieces: cortex, outer medulla, the outer $25 \%$ of inner medulla, and the inner $75 \%$ of inner medulla. These pieces were transferred into 
individual tubes containing $1 \mathrm{ml}$ of the same collagenase solution that was used to perfuse the kidney. The tubes were incubated for $30 \mathrm{~min}$ (cortex and outer medulla) or $40 \mathrm{~min}$ (inner medulla) at $37^{\circ} \mathrm{C}$ in a shaking water bath. The solutions were bubbled with $100 \%$ oxygen during these incubations. Then tissues were transferred to the dissection solution containing $10 \mathrm{mM}$ vanadyl ribonucleotide complex (Life Technologies Inc., Grand Island, NY), a potent ribonuclease (RNase) inhibitor, and they were placed on ice until microdissection.

Following previously described techniques (14), we microdissected the following structures: Glm, proximal convoluted tubule (PCT), cortical collecting ducts (CCD), arcuate artery, outer medullary collecting duct (OMCD), outer medullary thick ascending limb (MTAL), outer medullary vasa recta bundle, the initial part of inner medullary collecting duct (iIMCD), and the terminal part of inner medullary collecting duct (tIMCD). In the dissection of glomeruli, care was taken to remove all attached pieces of tubule, as well as afferent and efferent arterioles. PCT and CCD segments were obtained from medullary rays in cortical slices. The arcuate arteries were dissected from the junction of cortex and outer stripe of the outer medulla. MTAL, OMCD, and vasa recta were dissected from the inner stripe of outer medulla. The IMCD segments were dissected from the outer $25 \%$ of inner medulla (iIMCD) and the inner $75 \%$ of inner medulla (tIMCD).

The lengths of the dissected tubules were measured using a calibrated eyepiece micrometer. Generally, 2-mm lengths of the renal tubule segments or arcuate arteries were transferred to each assay tube, as indicated. Because it was impossible to separate individual vasa recta in a microdissected vascular bundle, we transferred entire bundles into the assay tubes for the RT-PCR procedure.

Microdissected structures were transferred to a separate wash-dish using a bent, polished, Pasteur pipette coated with $0.1 \%$ BSA (RNasefree, Boehringer Mannheim, GmBH, Mannheim, FRG). This washdish contained $10 \mathrm{ml}$ of the dissection solution. Microdissected tubules, Glm, and arcuate arteries and vasa rectas were washed free of contaminating debris and vanadyl ribonucleotide complex. These structures were transferred into the appropriate RT-PCR reaction tube, which contained $10 \mu$ l of ice-cold dissection solution containing $>1$ $\mathrm{U} / \mu \mathrm{l}$ of human placental RNase inhibitor (Boehringer Mannheim $\mathrm{GmBH}$ ) and $5 \mathrm{mM}$ DTT (Sigma Chemical Co.).

$R T$. RT was performed using a cDNA synthesis kit (Boehringer Mannheim $\mathrm{GmBH}$ ). The RNase-inhibitor solution was removed and 9 $\mu \mathrm{l}$ of $2 \%$ Triton X-100, containing $>1 \mathrm{U} / \mu \mathrm{l}$ of RNase-inhibitor, $5 \mathrm{mM}$ DTT, and 3 U RNase-free DNase (Pharmacia Fine Chemicals, Div. of Pharmacia Inc., Piscataway, NJ) was added to permeabilize the cells, followed by incubation at $37^{\circ} \mathrm{C}$ for $30 \mathrm{~min}$ to digest the genomic DNA. The samples were heated to $90^{\circ} \mathrm{C}$ for $5 \mathrm{~min}$ to inactivate the DNase. RT components were added to the reaction tubes as described previously (14) ( $\mu$ l): 4 buffer I, 1 RNase inhibitor, 2 deoxynucleotide mixture, 2 random primer, and 2 avian myeloblastoma virus reverse transcriptase. Reaction tubes were incubated at $42^{\circ} \mathrm{C}$ for $60 \mathrm{~min}$ in the Programmed Tempcontrol System (Astec, Tokyo, Japan). At the end of the incubation period, the reaction was stopped by heating at $90^{\circ} \mathrm{C}$ for $5 \mathrm{~min}$. This heat treatment also denatures RNA-cDNA hybrids and inactivates the reverse transcriptase. Then the reaction tubes were placed on ice until the addition of PCR reagents.

$P C R$. PCR was performed using the GeneAmp DNA Amplification Reagent Kit (Perkin-Elmer, Cetus Corporation, Emeryville, CA), with rat A-type ET-R- and B-type ET-R-specific primers prepared on a DNA synthesizer (Applied Biosystems, Tokyo, Japan). We designed specific primers $20-25$ nucleotides in length with $50-60 \%$ GC composition. The resultant high calculated melting temperature $\left(>75^{\circ} \mathrm{C}\right)$ allows a stringent annealing temperature in the PCR cycle. A-type ET-R primer 1 (antisense) was defined by bases 1172-1191, and primer 2 (sense) encompassed bases 405-424 (5). The sequence of A-type ET-R primer 1 was 5'-CGAGGTCATGAGGCTTTTGG-3'; primer 2 was 5'GTGTTTAAGCTGTTGGCGGG-3'. The predominant cDNA amplification product was predicted to be $787 \mathrm{bp}$ in length (the distance between primers plus primer length). A third oligonucleotide was synthesized to serve as an amplification product-specific probe. This oligo- nucleotide (sense) included bases 691-710 of the cDNA, positioned between primer 1 and primer 2 . The sequence of this oligonucleotide probe was 5'-TACAAGGGCGAGCAGCACAG-3'.

B-type ET-R primer 1 (antisense) was defined by bases 1418-1439, and primer 2 (sense) encompassed bases 521-545 (4). The sequence of B-type ET-R primer 1 was 5'-TGCACACCTTTCCGCAAGCACG-3'; primer 2 was 5'-AGCTGGTGCCCTTCATACAGAAGGC-3'. The predominant cDNA amplification product was predicted to be $919 \mathrm{bp}$ in length. A third oligonucleotide was synthesized to serve as an amplification product-specific probe. This oligonucleotide (sense) included bases $602-621$ of the cDNA, positioned between primer 1 and primer 2. The sequence of this oligonucleotide probe was 5'-CTGTTGCTTCTTGGAGTCGA-3'.

RT and PCR of glyceraldehyde-3-phosphate-dehydrogenase (GA$\mathrm{PDH}$ ) served as a positive control. The primers were defined by the following cDNA base sequences (15): primer 1 (antisense), bases 794813, sequence 5'-AGATCCACAACGGATACATT-3'; primer 2 (sense), bases 506-525, sequence 5'-TCCCTCAAGATTGTCAGCAA$3^{\prime}$. The cDNA amplification product was predicted to be $309 \mathrm{bp}$ in length. When we used GAPDH as an internal control primer, after RT, we divided $20-\mu \mathrm{l}$ samples to $15 \mu \mathrm{l}$ for A-type or B-type ET-R and $5 \mu \mathrm{l}$ for GAPDH. The volume was adjusted to $20 \mu \mathrm{l}$ with sterile water. Then we ran parallel PCR reactions with each set of primers.

To confirm that there is no cross-contamination of IMCD or glomerulus to other nephron segments, we used aldose reductase as a specific nephron marker. Aldose reductase was reported to be present in IMCD, inner medullary thin limb, and glomerulus $(13,16)$. The primers were defined by the following cDNA base sequences (13): primer 1 (antisense), bases 1276-1300, sequence 5'-CCCCCATAGGACTGGAGTTCTAAGC-3'; primer 2 (sense), bases 631-655, sequence, 5'-ACTGCCATTGCAAAGGCATCGTGGT-3'. The cDNA amplification product was predicted to be 670 bp in length.

To carry out the PCR, $80 \mu$ l of a PCR Master mix (Perkin-Elmer Cetus Corp., Emeryville, CA), prepared immediately before and containing all PCR components, was added to each tube directly. Total PCR volume was then $100 \mu$ l, including the original $20 \mu$ of RT reaction. 50 pmol of each of primers 1 and 2 was used per reaction for both A-type and B-type ET-R. Deoxynucleotides were added to a final concentration of $0.20 \mathrm{mM}$ each. Reaction buffer $(10 \times)$ was diluted $(1 / 10)$ to have a final composition of $10 \mathrm{mM}$ Tris- $\mathrm{HCl}, \mathrm{pH} 8.3 ; 50 \mathrm{mM} \mathrm{KCl}$; $1.5 \mathrm{mM} \mathrm{MgCl}_{2}$; and $0.001 \%$ (wt/vol) gelatin, $2.5 \mathrm{U}$ of Taq DNA polymerase.

$100 \mu \mathrm{l}$ of mineral oil was overlayed to prevent evaporation during the high temperature incubations. The tubes were placed in the Programmed Tempcontrol System (Astec) programmed as follows: $(a)$ incubation at $94^{\circ} \mathrm{C}$ for $3 \mathrm{~min}$ (initial melt); (b) 30 cycles of the following sequential steps: $94^{\circ} \mathrm{C}$ for $1 \mathrm{~min}$ (melt); $60^{\circ} \mathrm{C}$ for $1 \min$ (anneal); $72^{\circ} \mathrm{C}$ for $3 \mathrm{~min}$ (extend). (c) incubation at $72^{\circ} \mathrm{C}$ for $7 \mathrm{~min}$ (final extension). Then samples were kept at $4^{\circ} \mathrm{C}$ until the time of analysis.

$P C R$ product analysis. $90 \mu \mathrm{l}$ of the total reaction volume was ethanol precipitated (17). The PCR products were size-fractionated by agarose gel electrophoresis. After electrophoresis and ethidium bromide staining, DNA bands were visualized with an ultraviolet transilluminator (Funakoshi, Tokyo, Japan).

For Southern blot analysis, gels were denatured, neutralized, and blotted onto a nitrocellulose filter (Funakoshi) essentially as described by Maniatis et al. (17), with $20 \times$ standard sodium citrate (SSC; composition [M] 3 sodium chloride, 0.3 sodium citrate, $\mathrm{pH} 7.0$ ) as the transfer buffer. Blots were baked at $80^{\circ} \mathrm{C}$ for $4 \mathrm{~h}$ to fix the DNA. The synthetic oligonucleotide probes were end-labeled with ${ }^{32} \mathrm{P}$ as described previously (14). Prehybridization/hybridization washes were also the same as previously described (14).

To confirm that the PCR products were really A-type and B-type ET-R cDNAs, the PCR products were sequenced. PCR products from Glm were separated by gel electrophoresis. PCR products of A-type and B-type ET-R were subcloned into pGEM-3Zf(-) vector (Promega Boitec, Madison, WI), then sequenced using the dideoxynucleotide chain-termination reaction of Sanger et al. (18). 
Relative-quantitation of $m R N A$ levels from autoradiographs. The PCR products of B-type ET-R were detectable from several nephron segments. The relative amount of PCR products was determined by densitometer scanning of autoradiographs using a laser densitometer (Hoeler Scientific Instruments, San Francisco, CA). Each RT-PCR experiment included one or more tIMCD samples. For relative quantitation, we used the densitometry value from the tIMCD samples as an internal standard $(100 \%)$ and calculated the percentage of the tIMCD value for each segment.

To test the relationship between the quantity of starting material and that of amplification product as reflected by densitometry values, we compared amplification products from one, three, and five Glm.

Statistics. The results were given as mean \pm SEM. The differences were tested using analysis of variance. $P<0.05$ was considered significant.

\section{Results}

Relationship between the quantity of starting material and that of amplification product (Fig. 1). We compared amplification products from one, three, and five Glm. A typical gel is shown in the upper portion of Fig. 1. Assigning the five-Glm sample as an arbitrary unit of 100 , the values obtained were (mean \pm SEM, $n=5$ ) $25.5 \pm 4.8$ (one glomerulus) and $68.9 \pm 5.7$ (three Glm). Linear regression analysis showed a high correlation between densitometry values and the numbers of Glm ( $r$ $=0.99$ ).

Distribution of A-type ET-R mRNA in microdissected structures (Fig. 2). Each reaction was performed using either $2 \mathrm{~mm}$ of tubule length, $5 \mathrm{Glm}$, a single vasa recta bundle, or a 2-mm length of arcuate artery. A single band of predicted size (787 bp) was consistently found from the Glm, vasa recta, and arcuate artery (Fig. $2 \mathrm{~A}$ ). The Southern blots of the gels demonstrated specific binding of the oligonucleotide probe to the 787bp product (Fig. $2 \mathrm{~B}$ ). We confirmed that the PCR product has identical sequence to A-type ET-R cDNA by sequencing the subcloned PCR product. When the PCR procedure was carried out in the absence of reverse transcriptase, the 787-bp band was not seen and there was no other recognizable band. This indicated that the 787-bp band originated from mRNA, not from genomic DNA, which was presumably digested by DNase treatment. No band for A-type ET-R was detectable from any tubule segments. Therefore, we did not do relative-quantitative analysis of the PCR products for A-type ET-R. The amplifica-

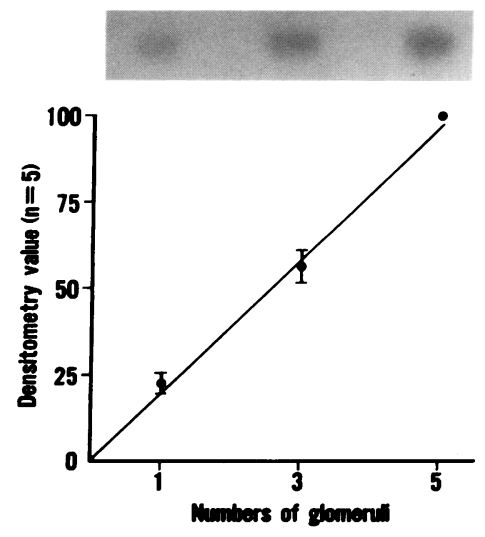

Figure 1. Densitometric analysis of the relationship between the quantity of starting material and the resulting amplification product for B-type ET-R mRNA. The upper portion of the figure is a typical autoradiogram. From left to right, the band originated from one, three, and five glomeruli. The data are the mean \pm SEM of five experiments from five rats. An arbitrary value of 100 was assigned to the sample representing five glomeruli.

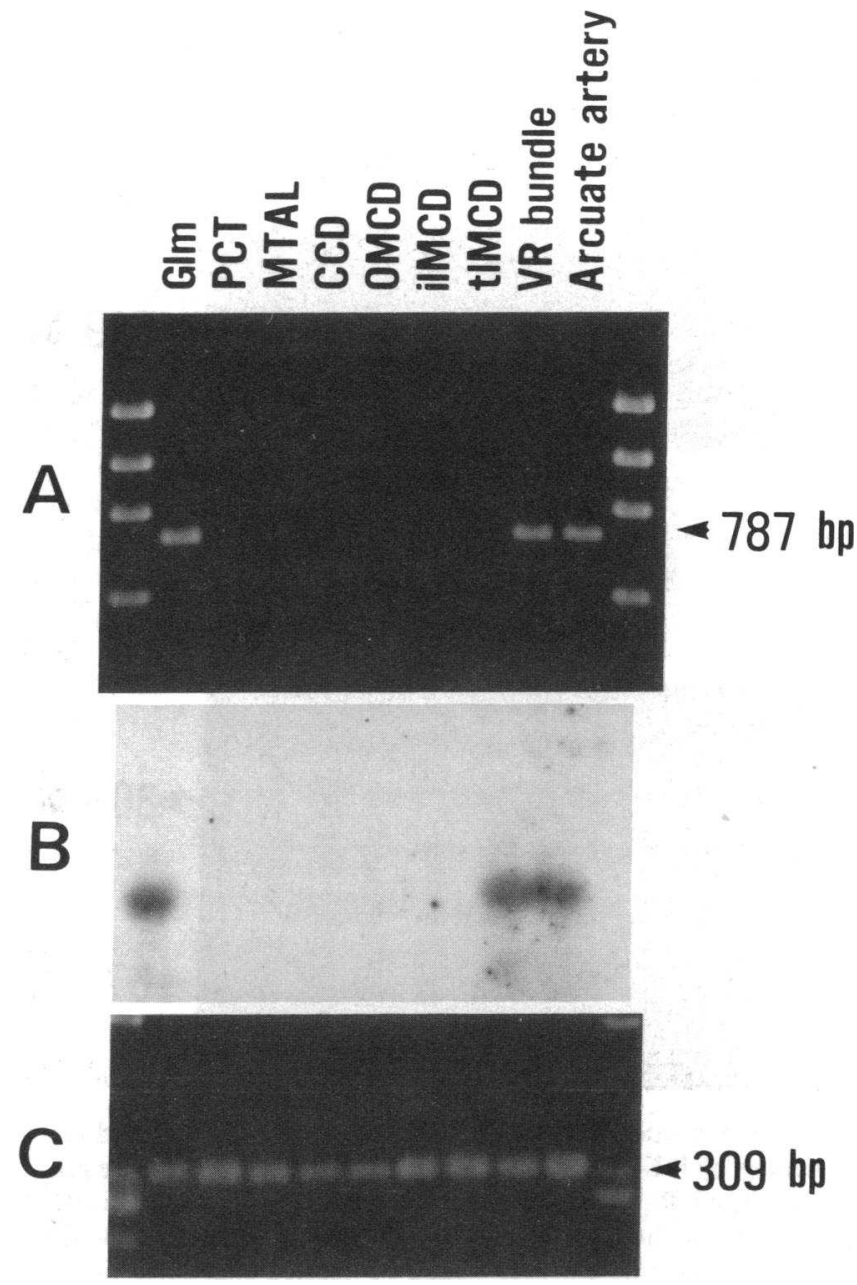

Figure 2. Detection of A-type ET-R mRNA in microdissected renal structures by RT-PCR. $(A)$ Ethidium bromide stained agarose gels for A-type ET-R. The arrow indicates expected PCR product size (787 bp). (B) Autoradiograms of corresponding Southern blots for A-type ET-R. The blots were probed with a ${ }^{32} \mathrm{P}$-labeled oligonucleotide that localized between the PCR primers. $(C)$ Ethidium bromide-stained agarose gel of GAPDH as positive control primers. The arrow indicates expected PCR products size (309 bp).

tion product of GAPDH was detected from all renal structures at predicted size (309 bp) and served as a positive control for the RT-PCR reaction (Fig. $2 C$ ).

Distribution of B-type ET-R $m R N A$ in microdissected structures (Fig. 3). A single band was consistently found from the GIm, iIMCD, tIMCD, OMCD, CCD, MTAL, and vasa recta for B-type ET-R (Fig. $3 A$ ). This band was the predicted size (919 bp). The Southern blots of the gels demonstrated specific binding of the oligonucleotide probe to the 919-bp product (Fig. $3 \mathrm{~B}$ ). We confirmed that the PCR product has identical sequence to B-type ET-R cDNA by sequencing the subcloned PCR product. When the PCR procedure was carried out in the absence of reverse transcriptase, the 919-bp band was not seen and there was no other recognizable band. Among renal tubule segments, the largest signal was consistently found in tIMCD. Furthermore, a large signal was consistently seen in iIMCD, and GIm. CCD and OMCD also showed pronounced bands. 


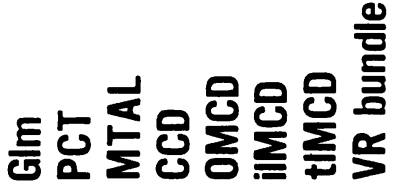
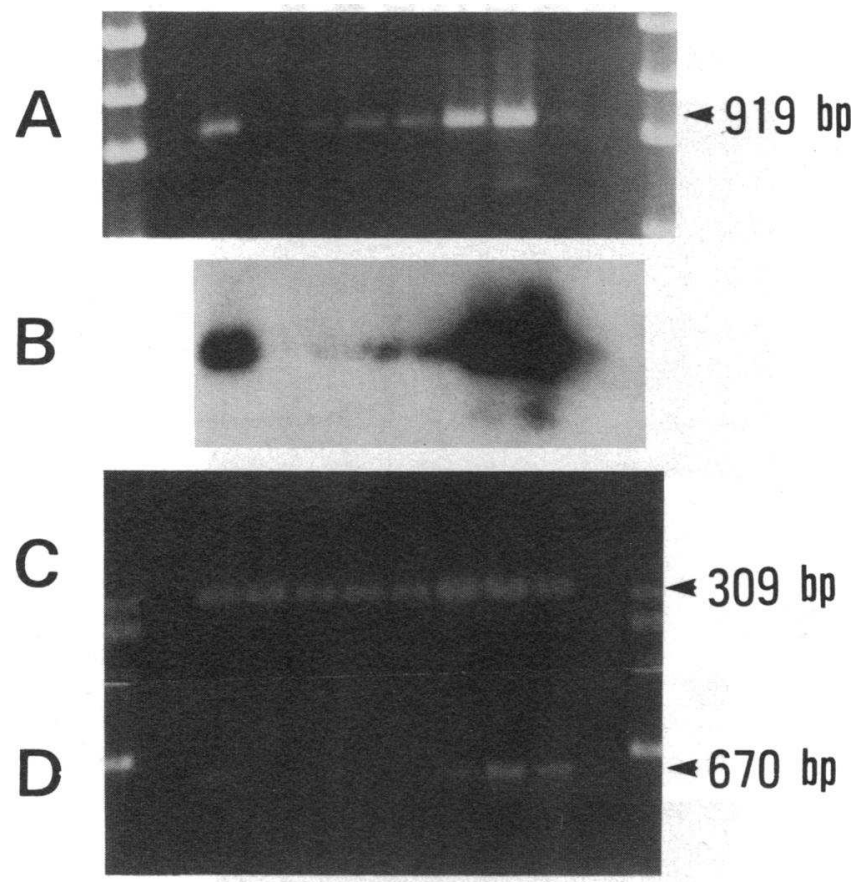

Figure 3. Detection of B-type ET-R mRNA in microdissected renal structures by RT-PCR. $(A)$ Ethidium bromide-stained agarose gels for B-type ET-R. The arrow indicates expected PCR product size (919 bp). (B) Autoradiograms of corresponding Southern blots for B-type ET-R. The blots were probed with a ${ }^{32} \mathrm{P}$-labeled oligonucleotide that localized between the PCR primers. $(C)$ Ethidium bromide-stained agarose gel of GAPDH as positive control primers. The arrow indicates expected PCR products size (309 bp). (D) Ethidium bromidestained agarose gel of aldose reductase as a specific nephron marker. The arrow indicates expected PCR products size (670 bp).

Small but detectable bands were observed from MTAL, vasa recta bundle, and arcuate artery (not shown in Fig. 3). The amplification product of GAPDH was detected from all renal structures at predicted size ( $309 \mathrm{bp})$ and served as a positive control for the RT-PCR reaction (Fig. $3 C$ ). Because we found the largest PCR signals of B-type ET-R from IMCD and glomerulus, cross-contamination of IMCD and glomerulus to other segments might cause false positive results. Distribution of aldose reductase mRNA, which was reported presented in IMCD, inner medullary thin limb, and glomerulus $(13,16)$, was studied to rule out the possibility that other segments were contaminated by IMCD or glomerulus. As shown in Fig. $4 D$, we did not detect any aldose reductase band in other segments. This suggested that there was no detectable cross-contamination between these segments. We detected a positive band of aldose reductase in the vasa recta bundle. However, the sample probably included medullary thin limbs because it is almost impossible to microdissect only vasa recta.

Relative levels of the B-type ET-R amplification products among the nephron segments (Fig. 4). The densitometer values are presented as percentages of the tIMCD value measured in

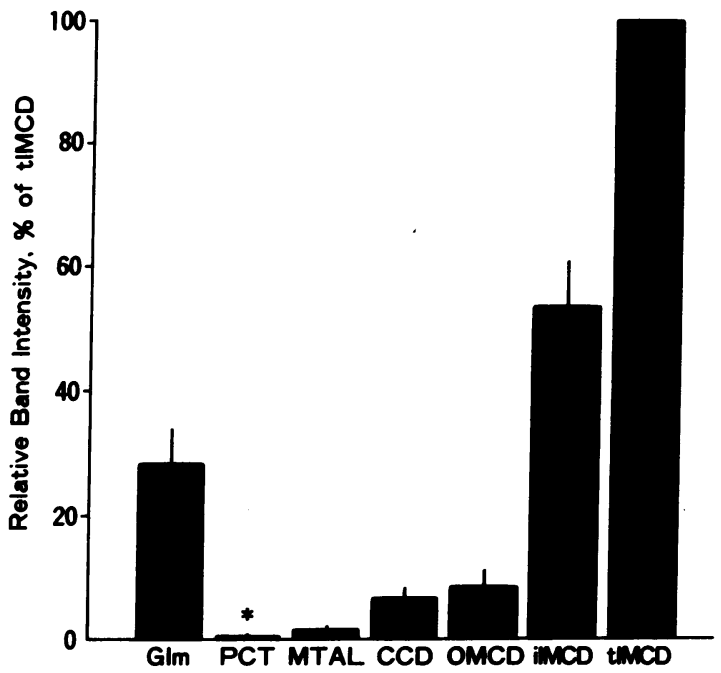

Figure 4. Relative quantitation of B-type ET-R mRNA in renal nephron segments. The values for each segment are expressed as a percentage of tIMCD values obtained in the same amplification run. The total number of each segment is five experiments from five rats. The value obtained from PCT was not significantly different from zero (indicated as *). Glm, glomerulus; $P C T$, proximal convoluted tubule; $M T A L$, medullary thick ascending limb; $C C D$, cortical collecting duct; $O M C D$, outer medullary collecting duct; $i I M C D$, initial inner medullary collecting duct; $t I M C D$, terminal inner medullary collecting duct.

the same experiment. Among collecting duct segments, the values were CCD, $6.8 \pm 2.0 \%(n=5)$; OMCD, $8.8 \pm 2.4 \%$; and iIMCD, $53.8 \pm 7.1 \%$. In proximal convoluted tubules, the signal was $0.3 \pm 0.1 \%$; this value was not significant from zero. The values in MTAL were $2.8 \pm 0.5 \%$. The signal from five Glm gave a relatively large signal, $28.5 \pm 5.6 \%$, compared with the signảl from 2-mm tIMCD.

\section{Discussion}

The sites of action of ET along the nephron have not been well defined. Our results show that the highest PCR signals for Btype ET-R were present in iIMCD and tIMCD. Moderate signals were obtained from the CCD and OMCD. These results suggest that the B-type ET-R may have a physiological function in the collecting duct system. We also detected significant signals from glomeruli for both A-type and B-type ET-R. We detected mainly A-type ET-R signal from the vasa recta bundle and from arcuate arteries.

ET increases urinary flow rate despite a decrease in GFR and renal blood flow (6). ET increases renal vascular resistance and contracts glomerular mesangial cells. These reports suggest that ET may influence glomerular function (7). Our results show that the glomerulus has both types of ET-R mRNA. The functional difference between A-type and B-type ET-R is not known, but the glomerular actions of ET may be the result of both A-type and B-type receptor functions. Another work indicated that ET decreased urinary sodium excretion, urine osmolality, and osmolar clearance, and increased free water clearance (19). Recently, we reported that ET specifically inhibited vasopressin-dependent cAMP accumulation in $C C D, O M C D$, and IMCD (20). Zeidel et al. (9) reported that ET inhibited 
Na-K-ATPase activity in IMCD cells. These reports suggest that ET has physiological roles in the distal nephron segments. We also reported that ET inhibited fluid absorption in rat CCD (20) and also inhibited arginine-vasopressin-stimulated osmotic water permeability in rat tIMCD (21). From our results, PCR signal for B-type ET-R was abundant in these segments, especially in initial and terminal IMCD, although we were not able to detect A-type ET-R signal from these segments. It seems likely that the ET has effects on the distal segments through B-type ET-R, but not A-type ET-R.

Many papers have reported on the renal binding sites of radiolabeled ET. Koseki et al. (10) found a high density of ET binding sites in the arcuate artery, vascular bundle, glomerulus, and papilla. Kohzuki et al. (11) reported similar results, showing that ET binding sites were present in the glomerulus, vascular system, and medulla. These binding studies used only radiolabeled ET-1, so these results could not distinguish between A-type and B-type ET-R. Although all of these reports demonstrated binding sites in renal papilla, it seemed difficult to determine whether the signals were from medullary collecting tubules or vasa recta. The advantage of our method is that we were clearly able to distinguish A-type and B-type ET-R because we selected specific primers for each receptor. In addition, we used microdissected identified structures, so it was relatively clear to determine which segments had signals. From our results, we can speculate the results of previous reports as follows: the bindings to the glomerulus are a combination of A-type and B-type ET-R, those to the vascular system represent mainly A-type ET-R, and those to the medulla are a combination of two signals, namely, B-type ET-R of medullary renal tubules and A-type ET-R of the vasa recta bundle.

The functional difference between A-type and B-type ET-R has not been well studied. ETs may elicit biological responses by various signal transduction mechanisms, including $G$ protein-coupled activation of phospholipase $C$ and phosphatidylinositol hydrolysis, and increasing cytosolic $\mathrm{Ca}^{2+}$ concentration in target cells (22). The possibility of another transduction system was also reported. ETs cause not only vasoconstriction, but also transient vasodilation, which may be evoked partly through the production of endothelium-derived relaxing factor $(2,23)$. Recently, Emori et al. (24) reported that ET-3 stimulates production of endothelium-derived nitric oxide in cultured bovine endothelial cells.

To understand the functional difference between A-type and B-type receptors, it is important to know the organ-specific mRNA expressions of each receptor. The mRNA for A-type and B-type ET-R shows different tissue distribution. B-type ET-R is widely expressed in brain, placenta, kidney, and a small amount in aorta (12) but is undetectable in a vascular smooth muscle cell line (A-10 cell) (4). By contrast, A-type ET-R mRNA is detected in heart, lung, brain, kidney, and aorta but is not expressed in endothelial cells (25). These reports suggest that the B-type ET-R is expressed in vascular endothelial cells, where it possibly mediates the release of endothelial-derived relaxing factor and prostacyclin $(1,12,26)$. ET has also been reported to stimulate prostaglandin $E_{2}$ and inhibit Na-K-ATPase activity (9). Our data showed that renal tubules express only B-type ET-R. Therefore, the renal tubular actions of ET may be mediated through endothelial-derived relaxing factor and prostacyclin, besides increasing cytosolic $\mathrm{Ca}^{2+}$ concentration.
Our approach to relative quantitation of the B-type ET-R PCR amplification product was to run Southern blots of the amplified cDNA using a ${ }^{32} \mathrm{P}$-labeled hybridization probe and then to assess the amount of bound radioactivity by densitometry of the resulting autoradiograms. The tIMCD consistently gave a large signal that was relatively invariant between replicates from experiment to experiment. Therefore we used the signal of tIMCD as an internal standard and expressed the densitometry values of other segments as percentages of tIMCD. For A-type ET-R, we detected positive signals only from the vascular system. We did not try relative quantitation of the signal because the anatomical structures of the glomerulus, arcuate artery, and vasa recta are completely different.

Other approaches to relative or absolute quantitation have been previously proposed, including competitive PCR (27) and PCR-aided transcript titration assay (PATTY) (28). Competitive PCR used a competitor cDNA whose sequence is the same as that of the target, except for the addition of either a short intron or an internal restriction enzyme target site. The competitor is added to the same samples and is coamplified, then the unknown samples are compared with the product of internal standard. This method does not account for the efficiency of the reverse transcription step and can give only relative, rather than absolute, quantitation of the number of mRNA molecules originally present. PCR-aided transcript titration assay is similar to competitive PCR, except that the internal standard is RNA that differs from the target mRNA by a single base substitution, creating a restriction site that allows it to be distinguished from the target. This method can potentially yield absolute quantitation of the specific target mRNA. However, it is unclear whether this approach would give adequate quantitation in microdissected tubules, because the efficiency of RT may be different between endogenous mRNA and the exogenous standards.

We chose a simple approach to relative quantitation rather than any of the complicated alternatives for several reasons. The ability of any method to yield absolute quantitation remains in question and would have to be carefully documented. The value of knowing the absolute number of mRNA molecules present in a given cell may be extremely limited for most physiological questions because there is presently no way to relate this number to the ultimate functional expression of the gene product.

We believe that our method gives a relative measure of the amount of specific B-type ET-R mRNA initially present in the cells. This conclusion is based on the observation that there is an approximately linear relationship between the number of glomeruli used for the assay (i.e., the amount of starting material) and the value obtained from densitometry of the amplification product band.

In summary, our data show that B-type ET-R mRNA distributes mainly in the collecting ducts and glomeruli, whereas A-type receptor mRNA is present only in the vascular system and glomeruli. This different distribution of two-type receptors suggests that two-type receptors and ET families play different roles to modulate renal functions.

\section{Acknowledgments}

The authors thank Dr. Robert A. Star, University of Texas Southwestern Medical Center, Dallas, TX, for critical review of the manuscript. 
We also thank Dr. Taihei Imai and Dr. Nobuyuki Enomoto, Tokyo Medical and Dental University, Tokyo, Japan, for help in sequence the PCR products.

This study was supported in part by a grant-in-aid for Scientific Research of Japan (02670273).

\section{References}

1. Yanagisawa, M., H. Kurihara, S. Kimura, Y. Tomobe, M. Kobayashi, Y. Mitsui, Y. Yazaki, K. Goto, and T. Masaki. 1988. A novel potent vasoconstrictor peptide produced by vascular endothelial cells. Nature (Lond.). 332:411-415.

2. Inoue, A., M. Yanagisawa, S. Kimura, Y. Kusuya, T. Miyauchi, K. Goto, and T. Masaki. 1989. The human endothelin family: three structurally and pharmacologically distinct isopeptides predicted by three separate genes. Proc. Natl. Acad. Sci. USA. 86:2863-2867.

3. Arai, H., S. Hori, I. Aramori, H. Ohkubo, and S. Nakanishi. 1990. Cloning and expression of a cDNA encoding an endothelin receptor. Nature (Lond.). 348:730-732.

4. Sakurai, T., M. Yanagisawa, Y. Takuwa, H. Miyazaki, S. Kimura, K. Goto, and T. Masaki. 1990. Cloning of a cDNA encoding a non-isopeptide-selective subtype of the endothelin receptor. Nature (Lond.). 348:732-735.

5. Lin, H. Y., E. H. Kaji, G. K. Winkel, H. E. Ives, and H. F. Lodish. 1991. Cloning and functional expression of a vascular smooth muscle endothelin 1 receptor. Proc. Natl. Acad. Sci. USA. 88:3185-3189.

6. Badr, K. F., J. J. Murray, M. D. Breyer, K. Takahashi, T. Inagami, and R. C. Harris. 1989. Mesangial cell, glomerular and renal vascular responses to endothelin in the rat kidney. J. Clin. Invest. 83:336-342.

7. Miller, W. L., M. M. Redfield, and J. C. Burnett, Jr. 1989. Integrated cardiac, renal, and endocrine actions of endothelin. J. Clin. Invest. 83:317-320.

8. Tomita, K., H. Nonoguchi, and F. Marumo. 1990. Effects of endothelin on peptide-dependent cyclic adenosine monophosphate accumulation along the nephron segments of the rat. J. Clin. Invest. 85:2014-2018.

9. Zeidel, M. L., H. R. Brady, B. C. Kone, S. R. Gullans, and B. M. Brenner. 1989. Endothelin, a peptide inhibitor of $\mathrm{Na} / \mathrm{K}-\mathrm{ATPase}$ in intact renal tubular epithelial cells. Am. J. Physiol. 257:C1101-C1107.

10. Koseki, C., M. Imai, Y. Hirata, M. Yanagisawa, and T. Masaki. 1989. Autoradiographic distribution in rat tissues of binding sites for endothelin: a neuropeptide? Am. J. Physiol. 256:R858-R866.

11. Kohzuki, M., C. I. Johnston, S. Y. Chai, D. J. Casley, and F. A. O. Mendelsoln. 1989. Localization of endothelin receptors in rat kidney. Eur. $J$. Pharmacol. 160:193-194.

12. Ogawa, Y., K. Nakao, H. Arai, O. Nakagawa, K. Hosoda, S. Suga, S. Nakanishi, and H. Imura. 1991. Molecular cloning of a non-isopeptide-selective human endothelin receptor. Biochem. Biophys. Res. Commun. 178:248-255.

13. Moriyama, T., H. R. Murphy, B. M. Martin, and A. Garcia-Perez. 1990.
Detection of specific mRNAs in single nephron segments by use of the polymerase chain reaction. Am. J. Physiol. 258:F1470-F1474.

14. Terada, Y., T. Moriyama, B. M. Martin, M. A. Knepper, and A. GarciaPerez. 1991. RT-PCR micro-localization of mRNA for guanylyl cyclase-coupled ANF receptor in rat kidney. Am. J. Physiol. 261:F1080-F1087.

15. Fort, P., L. Marty, M. Picchaczyk, S. E. Sabrouly, C. Dani, P. Jeanteur, and J. M. Blanchard. 1985. Various rat adult tissues exoress only one major mRNA species from the glyceraldehyde-3-phosphate-dehydrogenase multigene family. Nucleic Acids Res. 13:1431-1442.

16. Sands, J. M., Y. Terada, L. M. Bernard, and M. A. Knepper. 1989. Aldose reductase activities in microdissected rat renal tubule segments. Am. J. Physiol. 256:F563-F569.

17. Maniatis, T., E. Fritsch, and J. Sambrook. 1989. Molecular Cloning: A Laboratory Manual. Cold Spring Harbor Laboratory, Cold Spring Harbor, NY. $7 \cdot 2-7 \cdot 87$.

18. Sanger, F., S. Nicklen, and A. R. Coulson. 1977. DNA sequencing with chain-terminating inhibitors. Proc. Natl. Acad. Sci. USA. 74:5463-5467.

19. Goetz, K. L., B. C. Wang, J. B. Madwed, J. L. Zhu, and R. J. Leadley, Jr. 1988. Cardiovascular, renal, and endocrine responses to intravenous endothelin in conscious dogs. Am. J. Physiol. 255:R1064-R1068.

20. Tomita, K., H. Nonoguchi, and F. Marumo. 1990. Endothelin inhibits fluid absorption in rat cortical collecting ducts. J. Am. Soc. Nephrol. 1:427 (Abstr.).

21. Oishi, R., H. Nonoguchi, K. Tomita, and F. Marumo. 1992. Endothelin-1 inhibits AVP-stimulated osmotic water permeability in rat inner medullary collecting duct. Am. J. Physiol. 261:F951-F956.

22. Simonson, M. S., and M. J. Dunn. 1990. Cellular signaling by peptides of the endothelin gene family. FASEB (Fed. Am. Soc. Exp. Biol.) J. 4:2989-2995.

23. Fukuda, N., Y. Izumi, M. Soma, Y. Watanabe, M. Watanabe, M. Hatano, I. Sakuma, and H. Yasuda. 1990. L-N $\mathrm{N}^{\mathrm{G}}$-monomethyl arginine inhibits the vasodilating effects of low dose of endothelin-3 on rat mesenteric arteries. Biochem. Biophys. Res. Commun. 167:739-745.

24. Emori, T., Y. Hirata, K. Kanno, K. Ohta, S. Eguchi, T. Imai, M. Shichiri, and F. Marumo. 1991. Endothelin-3 stimulates production of endothelium-derived nitric oxide via phosphoinositide breakdown. Biochem. Biophys. Res. Commun. 174:228-235.

25. Hosoda, K., K. Nakao, H. Arai, S. Suga, Y. Ogawa, M. Mukoyama, G. Shirakami, Y. Saito, S. Nakanishi, and H. Imura. 1991. Cloning and expression of human endothelin-1 receptor cDNA. FEBS (Fed. Eur. Biochem. Soc.) Lett. 287:23-26.

26. Sakamoto, A., M. Yanagisawa, T. Sakurai, Y. Takuwa, H. Yanagisawa, and T. Masaki. 1991. Cloning and functional expression of human cDNA for the ETB endothelin receptor. Biochem. Biophys. Res. Commun. 178:656-663.

27. Gilliland, G., S. Perrin, K. Blanchard, and H. F. Bunn. 1990. Analysis of cytokine mRNA and DNA: detection and quantitation by competitive polymerase chain reaction. Proc. Natl. Acad. Sci. USA. 87:2725-2729.

28. Becker-Andre, M., and K. Hahlbrock. 1989. Absolute mRNA quantification using the polymerase chain reaction (PCR). A novel approach by a PCRaided transcript titration assay (PATTY). Nucleic Acids Res. 17:9437-9446. 